\title{
Adaptabilidade e estabilidade fenotípica de genótipos de amendoim de porte ereto
}

\author{
Lidinalva de Resende Gomes ${ }^{(1)}$, Roseane Cavalcanti dos Santos( ${ }^{(2)}$, Clodoaldo José da Anunciação Filho(1) \\ e Péricles de Albuquerque Melo Filho(1)
}

\begin{abstract}
(1)Universidade Federal Rural de Pernambuco, Dep. de Agronomia, Rua D. Manuel de Medeiros, s/no, Dois Irmãos, CEP 52171-900 Recife, PE. E-mail: lidinalvar@yahoo.com.br, cjoseufrpe@yahoo.com.br, pericles@depa.ufrpe.br (2)Embrapa Algodão, Caixa Postal 174, CEP 58107-720 Campina Grande, PB. E-mail: caval@cnpa.embrapa.br
\end{abstract}

\begin{abstract}
Resumo - O objetivo deste trabalho foi estimar os parâmetros de adaptabilidade e estabilidade de nove genótipos de amendoim, a partir dos dados de produtividade em vagens e sementes, em oito ambientes do Estado de Pernambuco. O delineamento experimental utilizado foi o de blocos ao acaso, com cinco repetições. Para análise dos parâmetros de estabilidade, adotou-se o método de Eberhart \& Russell. No aspecto produtividade, verificou-se que os genótipos BR1, BRS Havana, BRS 151 L7, CNPA 280 AM e L7 Beje destacaram-se na produção de vagens e sementes, com médias de $3.106 \mathrm{~kg} \mathrm{ha}^{-1} \mathrm{e} 2.068 \mathrm{~kg} \mathrm{ha}^{-1}$, respectivamente. Considerando-se a produtividade de vagens e sementes, verificou-se que a cultivar BRS $151 \mathrm{L7}$, além de produtiva, possui ampla adaptabilidade e comportamento previsível nos ambientes estudados, enquanto os genótipos BR 1, BRS Havana e L7 Beje apresentam ampla adaptabilidade e alta estabilidade apenas quanto à produtividade de sementes.
\end{abstract}

Termos para indexação: Arachis hypogaea, interação genótipo x ambiente, produtividade.

\section{Fenotypical adaptability and stability of upright peanut genotypes}

\begin{abstract}
The objective of this work was to estimate stability and adaptability parameters, related to pod and seed yields, of nine peanut genotypes evaluated in eight environments of Pernambuco State, Brazil. A randomized block design was used with five replicates. The method of Eberhart \& Russell was utilized. The genotypes BR1, BRS Havana, BRS 151 L7, CNPA 280 AM e L7 Beje showed high pod and seed production, with yield averages of 3,106 $\mathrm{kg} \mathrm{ha}^{-1}$ and 2,068 $\mathrm{kg} \mathrm{ha}^{-1}$, respectively. However, taking into account both pod and seed yields, BRS $151 \mathrm{~L} 7$ showed high production, broad adaptability and previsible behavior in the environmental conditions evaluated; and genotypes BR 1, BRS Havana and L7 Beje were also highly adapted and stable, but only for seed yield.
\end{abstract}

Index terms: Arachis hypogaea, genotype x environment interaction, productivity.

\section{Introdução}

O amendoim é uma excelente alternativa agrícola para a região Nordeste do Brasil, em razão da riqueza nutricional de suas sementes e adaptação às condições semi-áridas (Freitas et al., 2005). A produção obtida na região é baixa, cerca de 14 mil toneladas, e corresponde apenas a 30\% da demanda; o restante é importado principalmente de São Paulo e Argentina (Santos et al., 2005).

Segundo Godoy et al. (2005), a região Nordeste apresenta grande potencial para a cultura, por suas condições edafoclimáticas favoráveis e pela necessidade de diversificação agrícola, principalmente no preenchimento de espaços deixados pela cana-de-açúcar e algodão. A cultura tem ciclo curto, é de fácil manejo e apresenta mercado atraente. Cerca de $70 \%$ da área cultivável no Nordeste encontra-se em condições semiáridas, o que torna potencialmente interessante a produção dessa oleaginosa, desde que se tenha cultivares adaptadas a essas condições.

A identificação de genótipos com alta produtividade, estabilidade de produção e ampla adaptabilidade aos mais variados ambientes é um dos principais objetivos dos programas de melhoramento. A condução de experimentos, em vários locais e anos, faz-se necessária por diminuir o efeito da interação GxA e seu possível impacto sobre a seleção e indicação de cultivares. Tal procedimento é imprescindível para se assegurar maior confiabilidade na recomendação de cultivares (Cruz \& Castoldi, 1991; Sudaric et al., 2006). O estudo dos parâmetros de 
adaptabilidade e estabilidade fenotípica dos genótipos tem sido de grande contribuição nesse aspecto, pois fornece informações sobre o comportamento de cada genótipo, em várias condições ambientais (Cruz, et al., 2004).

Há vários métodos de análise de adaptabilidade e estabilidade destinados à avaliação de um grupo de genótipos. Entre eles, o proposto por Eberhart \& Russell (1966) é um dos mais utilizados, pois fornece maiores informações na indicação de linhagens mais produtivas e facilidade para estimar e interpretar os parâmetros obtidos. Uma vantagem deste método é a de que ele considera cada ensaio como um ambiente, independentemente do ano agrícola ou sistema de cultivo (Silva \& Duarte et al., 2006). Ainda com relação à essa metodologia, o comportamento de cada genótipo, nas variações ambientais, é estimado por meio de análise de regressão linear simples.

Segundo Távora et al. (2002), a maioria das linhagens avaliadas nos programas de melhoramento de amendoim apresenta comportamento linear. Assim, considera-se um genótipo ideal aquele com produtividade média alta, coeficiente de regressão igual a 1 e desvio da regressão o menor possível. Oliveira et al. (2006) recomendam o uso de métodos baseados em coeficientes de regressão, que são eficientes na discriminação de genótipos produtivos com ampla adaptabilidade.

Para a cultura do amendoim, os parâmetros de adaptabilidade e estabilidade têm sido largamente estudados, com predominância do método proposto por Eberhart \& Russell (1966). Esses estudos têm subsidiado o melhoramento e o lançamento de cultivares em vários estados brasileiros (Távora et al., 1988; Godoy et al., 1999; Santos et al., 1999; Coutinho et al., 2002; Távora et al., 2002; Oliveira et al., 2006).

O objetivo deste trabalho foi estimar os parâmetros de adaptabilidade e estabilidade de nove genótipos de amendoim, a partir dos dados de produtividade em vagens e sementes, em oito ambientes do Estado de Pernambuco.

\section{Material e Métodos}

Foram avaliados nove genótipos de amendoim cinco linhagens e quatro cultivares - pertencentes ao ensaio de linhagens avançadas da Embrapa Algodão (Tabela 1). A cultivar Tatu foi utilizada como testemunha, por ser a mais cultivada no País. Os experimentos foram conduzidos durante três anos (2004 a 2006), em seis municípios que representam as microrregiões do Agreste, da Zona da Mata, do Sertão pernambucano e Litoral/Mata (Tabela 2).

Tabela 1. Genealogia e alguns descritores agronômicos de genótipos de amendoim, pertencentes ao ensaio de linhagens avançadas da Embrapa Algodão ${ }^{(1)}$.

\begin{tabular}{|c|c|c|c|c|c|c|c|}
\hline \multirow[t]{2}{*}{ Genótipo } & \multirow[t]{2}{*}{ Genealogia } & \multicolumn{3}{|c|}{ Semente } & \multirow{2}{*}{$\begin{array}{l}\text { Sementes } \\
\text { por vagem }\end{array}$} & \multirow{2}{*}{$\begin{array}{l}\text { Vagens por } \\
\text { planta }\end{array}$} & \multirow{2}{*}{$\begin{array}{c}\text { P100S } \\
\text { (g) }\end{array}$} \\
\hline & & Cor & Tamanho & Forma & & & \\
\hline$\overline{\mathrm{BR} 1}$ & Cultivar & $\mathrm{V}$ & $\mathrm{M}$ & $\mathrm{Ar}$ & $3-4$ & 21 & 43 \\
\hline BRS Havana & Cultivar & B & M & $\mathrm{Ar}$ & $3-4$ & 20 & 50 \\
\hline BRS 151 L7 & Cultivar & V & $\mathrm{G}$ & $\mathrm{Al}$ & $1-2$ & 20 & 67 \\
\hline CNPA 280 AM & Manfredi 407 x Florunner ${ }^{(2)}$ & B & $\mathrm{M}$ & $\mathrm{Al}$ & $2-3$ & 20 & 47 \\
\hline L7 Beje & IAC Tupã x Senegal $55437^{(2)}$ & B & G & $\mathrm{Al}$ & $1-2$ & 18 & 61 \\
\hline CNPA 283 AM & Manfrendi x Florunner ${ }^{(2)}$ & B & M & $\mathrm{Ar}$ & $2-3$ & 17 & 51 \\
\hline CNPA 271 AM & Manfredi 407 x Manfredi 424(2) & V & M & $\mathrm{Ar}$ & $2-3$ & 19 & 46 \\
\hline Tatu & Cultivar & $\mathrm{V}$ & M & $\mathrm{Ar}$ & $3-4$ & 15 & 39 \\
\hline CNPA 270 AM & Manfredi 407 x Manfredi $424^{(2)}$ & $\mathrm{V}$ & $\mathrm{P}$ & $\mathrm{Ar}$ & $2-3$ & 14 & 43 \\
\hline
\end{tabular}

${ }^{(1)}$ B: beje; V: vermelho; M: médio; P: pequeno; G: grande; Ar: arredondada; Al: alongada; P100S: peso de 100 sementes. ${ }^{(2)}$ Linhagem avançada $\left(\mathrm{F}_{8}\right)$.

Tabela 2. Coordenadas geográficas, altitude e precipitação pluvial média registrada durante o cultivo de amendoim nos ambientes estudados

\begin{tabular}{lccccc}
\hline Local & Latitude & Longitude & Altitude $(\mathrm{m})$ & Precipitação $(\mathrm{mm})$ & Textura do solo \\
\hline Araripina & $7^{\circ} 29^{\prime} \mathrm{S}$ & $40^{\circ} 36^{\prime} \mathrm{W}$ & 816 & 654 & Franco-arenosa \\
Bonito & $8^{\circ} 30^{\prime} \mathrm{S}$ & $35^{\circ} 47^{\prime} \mathrm{W}$ & 591 & 538 & Franco-arenosa \\
Carpina & $7^{\circ} 51^{\prime} \mathrm{S}$ & $35^{\circ} 15^{\prime} \mathrm{W}$ & 178 & 806 & Franco-argilosa \\
Goiana & $7^{\circ} 42^{\prime} \mathrm{S}$ & $34^{\circ} 56^{\prime} \mathrm{W}$ & 72 & 568 & Arenosa \\
Recife & $8^{\circ} 01^{\prime} \mathrm{S}$ & $34^{\circ} 56^{\prime} \mathrm{W}$ & 21 & 840 & Franco-argilosa \\
Parnamirim & $8^{\circ} 15^{\prime} \mathrm{S}$ & $39^{\circ} 07^{\prime} \mathrm{W}$ & 398 & 478 & Franco-arenosa \\
\hline
\end{tabular}

Fonte: ITEP (2006). 
Os ensaios foram conduzidos durante a estação chuvosa de cada local, entre os meses de maio e junho. Os tratos culturais e fitossanitários foram realizados segundo a recomendação de Santos et al. (1996). $\mathrm{O}$ espaçamento adotado foi $0,7 \times 0,2 \mathrm{~m}$, tendo-se deixado duas plantas por cova. O delineamento experimental adotado foi o de blocos ao acaso, com cinco repetições. A colheita foi efetuada entre 85 e 90 dias após o plantio. Para o estudo de adaptabilidade e estabilidade, utilizaramse os dados de produtividade de vagens e de sementes.

A partir dos dados obtidos, procedeu-se à análise de variância para cada ambiente e, posteriormente, à análise de variância conjunta, para testar os efeitos de genótipos (G), ambientes (A) e a magnitude da interação GxA (Ramalho et al., 2005). A homogeneidade das variâncias residuais dos experimentos foi testada e, em seguida, realizou-se o ajuste dos graus de liberdade do resíduo e da interação GxA, conforme o método de Cochran (1954), citado por Pimentel-Gomes (1990).

Os parâmetros de adaptabilidade e estabilidade foram estimados segundo o método de Eberhart \& Russell (1966), que se baseia no modelo de regressão linear da produtividade de cada genótipo com as variações ambientais, quer seja: $Y_{i j}=\mu_{i}+\beta_{i} I_{j}+\delta_{i j}+\varepsilon_{i j}$, em que $\mathrm{Y}_{\mathrm{ij}}$ é a média de produtividade do genótipo $\mathrm{i}$, no ambiente $\mathrm{j} ; \mu_{\mathrm{i}}$ representa a média geral do genótipo, em todos os ambientes; $\beta_{\mathrm{i}}$ corresponde ao coeficiente de regressão linear da resposta do genótipo i a todos os ambientes; $\mathrm{I}_{\mathrm{j}}$ é o índice ambiental; $\delta_{\mathrm{ij}}$ corresponde aos desvios de regressão do genótipo i, no ambiente j; e $\varepsilon_{\mathrm{ij}}$ é o resíduo da regressão do genótipo i, no ambiente $\mathrm{j}$.

Todas as análises experimentais foram realizadas com auxílio do programa GENES (Cruz, 2006).

\section{Resultados e Discussão}

A análise da variância conjunta, baseada nos dados de produtividade de vagens e de sementes, encontra-se na Tabela 3. Os efeitos de interação GxA foram significativos para as duas variáveis, o que indica resposta diferencial na produtividade dos genótipos, em conseqüência dos ambientes estudados. As estimativas dos parâmetros de adaptabilidade e estabilidade fenotípica dos genótipos, quanto à produtividade de vagens e sementes, estão apresentadas na Tabela 4. Observou-se que os genótipos BR1, BRS Havana, BRS 151 L7, CNPA 280 AM e L7 Beje situaram-se no mesmo grupo estatístico; destacaram-se quanto à produção média de vagens (3.106 kg ha-1) e de sementes ( $\left.2.068 \mathrm{~kg} \mathrm{ha}^{-1}\right)$ e superaram a testemunha Tatu em 14 e 13\%, respectivamente. No entanto, apenas BR 1 diferiu estatisticamente da Tatu, e a superou em $19 \%$, nas duas variáveis. A média de rendimento em sementes desses materiais situou-se em $67 \%$, com variações entre 63\% para CNPA 283 AM e $69 \%$ para CNPA 280 AM (Tabela 4). O rendimento ideal é de $70 \%$ e é influenciado pelas condições de fertilidade e do $\mathrm{pH}$ do solo (Santos et al., 2005).

No aspecto adaptabilidade, verificou-se que todos os genótipos apresentaram ampla adaptação aos ambientes estudados, quanto à produtividade em vagens e em sementes, com exceção da CNPA $280 \mathrm{AM}\left(\beta_{\mathrm{i}}=1,31^{* * *}\right.$ e $1,43^{* *}$, respectivamente), que se apresentou com adaptabilidade específica a ambientes favoráveis (Tabela 4). Em relação à estabilidade, verificou-se que o genótipo BRS 151 L7 comportou-se como o mais estável. Em relação à variável produtividade de sementes, todos genótipos apresentaram-se como estáveis.

Verificou-se que a cultivar BRS 151 L7 apresentou ampla adaptação e comportamento previsível, para as duas variáveis estudadas, com rendimentos médios de vagens e sementes superiores à média geral em 6 e 7\%, respectivamente. Os genótipos BR 1, BRS Havana e L7 Beje também apresentaram ampla adaptabilidade e alta estabilidade, porém, apenas quanto à produtividade de sementes.

De acordo com Santos (2000), a cultivar BRS 151 L7 possui grande potencial produtivo e larga adaptação às condições da região Nordeste. Trata-se de material de grande precocidade, com ciclo de apenas 85 dias (Santos et al., 2005).

Tabela 3. Análise de variância conjunta, quanto à produtividade de vagens e de sementes dos genótipos de amendoim, em oito ambientes $^{(1)}$.

\begin{tabular}{lccc}
\hline $\begin{array}{l}\text { Fonte de } \\
\text { variação }\end{array}$ & GL & \multicolumn{2}{c}{ Quadrado médio } \\
\cline { 3 - 4 } & & $\begin{array}{c}\text { Produtividade de } \\
\text { vagens }\left(\mathrm{kg} \mathrm{ha}^{-1}\right)\end{array}$ & $\begin{array}{c}\text { Produtividade de } \\
\text { sementes }\left(\mathrm{kg} \mathrm{ha}^{-1}\right)\end{array}$ \\
\hline Bloco/ambiente & 24 & $448.382,18^{\mathrm{ns}}$ & $277.148,31^{\mathrm{ns}}$ \\
Genótipo (G) & 8 & $1.264 .588,69^{* *}$ & $757.720,41^{* *}$ \\
Ambiente (A) & 7 & $2.227 .4995,64^{* *}$ & $7.775 .510,41^{* *}$ \\
GxA & $56(39)^{(1)}$ & $892.177,45^{*}$ & $504.307,76^{*}$ \\
Resíduo & $192(127)$ & $257.128,99$ & $145.748,26$ \\
\hline Média & & 2.959 & 1.957 \\
CV $(\%)$ & & 17,13 & 10,49 \\
\hline
\end{tabular}

${ }^{(1)}$ Dados entre parênteses representam o grau de liberdade, corrigido pelo método de Cochran (1954), citado por Pimentel-Gomes (1990), em

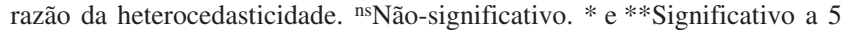
e $1 \%$ de probabilidade, respectivamente, pelo teste $\mathrm{F}$. 
Tabela 4. Estimativas dos parâmetros de adaptabilidade e estabilidade fenotípica, quanto à produtividade de vagens e de sementes, segundo o modelo proposto por Eberhart \& Russell $(1966)^{(1)}$.

\begin{tabular}{|c|c|c|c|c|c|c|c|}
\hline \multirow[t]{2}{*}{ Genótipo } & \multicolumn{3}{|c|}{ Produtividade de vagens $\left(\mathrm{kg} \mathrm{ha}^{-1}\right)$} & \multicolumn{4}{|c|}{ Produtividade de sementes $\left(\mathrm{kg} \mathrm{ha}^{-1}\right)$} \\
\hline & Média & $\beta_{\mathrm{i}}$ & $\delta_{\mathrm{ij}}\left(\mathrm{x} 10^{4}\right)$ & Média & $\beta_{\mathrm{i}}$ & $\delta_{\mathrm{ij}}\left(\mathrm{x} 10^{4}\right)$ & $\begin{array}{l}\text { Rendimento em } \\
\text { sementes }(\%)\end{array}$ \\
\hline$\overline{\text { BR } 1}$ & $3.243 a$ & $0,84^{\mathrm{ns}}$ & $19,89 * *$ & $2.171 \mathrm{a}$ & $0,85^{\mathrm{ns}}$ & $-1.589,15^{\mathrm{ns}}$ & 67 \\
\hline BRS Havana & $3.174 \mathrm{ab}$ & $0,82^{\text {ns }}$ & $6,34^{*}$ & $2.115 \mathrm{ab}$ & $0,83^{\mathrm{ns}}$ & $-1.599,76^{\mathrm{ns}}$ & 67 \\
\hline BRS 151 L7 & $3.148 \mathrm{abc}$ & $0,95^{\mathrm{ns}}$ & $0,50^{\mathrm{ns}}$ & $2.090 \mathrm{ab}$ & $0,96^{\mathrm{ns}}$ & $-1.600,06^{\mathrm{ns}}$ & 66 \\
\hline CNPA 280 AM & $3.015 \mathrm{abc}$ & $1,31 * *$ & $30,47 * *$ & $2.091 \mathrm{ab}$ & $1,43 * *$ & $-1.578,64^{\mathrm{ns}}$ & 69 \\
\hline L7 Beje & $2.948 \mathrm{abc}$ & $0,87^{\mathrm{ns}}$ & $6,83^{*}$ & $1.872 \mathrm{ab}$ & $0,75^{\mathrm{ns}}$ & $-1.597,48^{\mathrm{ns}}$ & 64 \\
\hline CNPA 283 AM & $2.869 \mathrm{abc}$ & $1,02^{\mathrm{ns}}$ & $8,16^{* *}$ & $1.821 \mathrm{~b}$ & $0,99^{\mathrm{ns}}$ & $-1.598,09^{\mathrm{ns}}$ & 63 \\
\hline CNPA 271 AM & $2.788 \mathrm{bc}$ & $1,12^{\mathrm{ns}}$ & $10,64 * *$ & $1.829 \mathrm{~b}$ & $1,10^{\mathrm{ns}}$ & $-1.598,94^{\mathrm{ns}}$ & 66 \\
\hline Tatu & $2.734 b c$ & $0,95^{\mathrm{ns}}$ & $1,34^{\mathrm{ns}}$ & $1.826 \mathrm{~b}$ & $1,01^{\mathrm{ns}}$ & $-1.599,23^{\mathrm{ns}}$ & 67 \\
\hline CNPA 270 AM & $2.709 \mathrm{c}$ & $1,06^{\mathrm{ns}}$ & $5,91 *$ & $1.803 \mathrm{~b}$ & $1,01^{\mathrm{ns}}$ & $-1.598,12^{\mathrm{ns}}$ & 66 \\
\hline Média & 2.959 & & & 1.957 & & & 67 \\
\hline
\end{tabular}

${ }^{(1)}$ Médias seguidas por letras iguais não diferem entre si, pelo teste de Duncan, a $5 \%$ de probabilidade. * e **Significativo a 5 e $1 \%$ de probabilidade, pelo teste $\mathrm{t}\left(\beta_{\mathrm{i}}\right)$ e $\mathrm{F}\left(\delta_{\mathrm{ij}}\right)$.

Os resultados obtidos neste trabalho estão de acordo com os desenvolvidos por outros autores na Região Nordeste. Santos et al. (1999) realizaram estudos de estabilidade em dez genótipos de amendoim de porte ereto, em dez ambientes concentrados nos estados de Pernambuco, Bahia, Sergipe e Paraíba, e verificaram que a cultivar BR 1 destacou-se entre as demais pela produtividade de vagens, e que é de ampla adaptação e alta estabilidade para a Região Nordeste. Em Pernambuco, Coutinho et al. (2002) conduziram ensaios na Chapada do Araripe e verificaram que a cultivar BRS Havana apresenta alta previsibilidade de comportamento, tanto para produtividade de vagens quanto de sementes.

No Brasil, os tipos de amendoim cultivados são, na maioria, de hábito de crescimento ereto, e são cultivados em razão do menor ciclo (em torno de 90 dias) e da facilidade na colheita. Outro tipo utilizado é o de hábito rasteiro, mais concentrado nas regiões Sudeste e Centro-Oeste, em sistemas de cultivo tecnicizados; cultivares deste tipo, embora mais produtivas, têm ciclo longo (entre 130 e 150 dias) e, freqüentemente, menor adaptação às condições de clima do Nordeste (Godoy et al., 2005). Para essa região, os tipos eretos são mais recomendados pela maior adaptação climática e menor ciclo. Em programas de melhoramento voltados para o Nordeste, Santos et al. $(1999,2005)$ reportaram que a associação dessas características, aliadas à produtividade e precocidade, é imprescindível na obtenção de uma cultivar. Távora et al. (2002) testaram oito genótipos de amendoim de porte ereto e rasteiro, em Fortaleza, e concluíram que os genótipos rasteiros são mais instáveis e menos previsíveis, e que os eretos atingem maior grau de adaptação sob condições limitadas e de irregularidade de disponibilidade hídrica.

\section{Conclusões}

1. A cultivar BRS 151 L7 apresenta ampla adaptabilidade e alta estabilidade, para produção de vagens e sementes, e é a mais recomendada para os ambientes estudados.

2. Os genótipos BR 1, BRS Havana e L7 Beje são de ampla adaptação e comportamento previsível quanto à produtividade de sementes.

\section{Agradecimentos}

À Petrobras e ao Programa Fome Zero, pelo financiamento da pesquisa; à Embrapa Algodão, pelo fornecimento das sementes; à Capes pela concessão de bolsa; ao pesquisador Odemar Vicente dos Reis, pela colaboração nas análises estatísticas.

\section{Referências}

COUTINHO, J.L.B.; TAVARES, J.A.; SANTOS, V.F.; SANTOS, R.C.; CARVALHO NETO, A. Estabilidade e adaptabilidade de genótipos de amendoim (Arachis hypogaea L.) na chapada do Araripe, em Pernambuco. Pesquisa Agropecuária Pernambucana, v.13, p.17-24, 2002.

CRUZ, C.D. Programa GENES: aplicativo computacional em genética e estatística experimental (software). Viçosa: UFV, 2006. CRUZ, C.D.; CASTOLDI, F.L. Decomposição da interação genótipos x ambiente em partes simples e complexa. Revista Ceres, v.38, p.422-430, 1991. 
CRUZ, C.D.; REGAZZI, A.J.; CARNEIRO, P.C.S. Modelos biométricos aplicados ao melhoramento genético. Viçosa: UFV, 2004. p.103-165.

EBERHART, S.A.; RUSSELL, W.A. Stability parameters for comparing varieties. Crop Science, v.6, p.36-40, 1966.

FREITAS, S.M.; MARTINS, S.S.; NOMI, A.K.; CAMPOS, A.F. Evolução do mercado brasileiro de amendoim. In: SANTOS, R.C. (Ed.). O agronegócio do amendoim no Brasil. Campina Grande: Embrapa Algodão; Brasília: Embrapa Informação Tecnológica, 2005. p.15-44.

GODOY, I.J.; MORAES, S.A.; SIQUEIRA, W.J.; PEREIRA, J.C.N.A.; MARTINS, A.L.M.; PAULO, E.M. Produtividade, estabilidade e adaptabilidade de cultivares de amendoim em três níveis de controle de doenças foliares. Pesquisa Agropecuária Brasileira, v.34, p.1183-1191, 1999.

GODOY, I.J.; MORAES, S.A.; ZANOTTO, M.D.; SANTOS, R.C. Melhoramento do amendoim. In: BORÉM, A. Melhoramento de espécies cultivadas. Viçosa: UFV, 2005. p.54-95.

ITEP. Instituto de Tecnologia de Pernambuco. Dados de chuvas de 2005 e 2006. Disponível em : www.itep.br/LAMEPE.asp. Acesso: 10 de novembro de 2006.

OLIVEIRA, E.J.; GODOY, I.G.; MORAES, A.R.A.; MARTINS, A.L.M.; PEREIRA, J.C.V.N.A.; BORTOLETTO, N.; KASAI, F.S. Adaptabilidade e estabilidade de genótipos de amendoim de porte rasteiro. Pesquisa Agropecuária Brasileira, v.41, p.1253-1260, 2006.

PIMENTEL-GOMES, F. Curso de estatística experimental. 13.ed. Piracicaba: Nobel, 1990. 468p.

RAMALHO, M.A.P.; FERREIRA, D.F.; OLIVEIRA, A.C. Experimentação em genética e melhoramento de plantas. Lavras: UFLA, 2005. 300p.

SANTOS, R.C. BRS L7: Nova cultivar de amendoim para as condições do Nordeste brasileiro. Pesquisa Agropecuária Brasileira, v.35, p.665-670, 2000.
SANTOS, R.C.; FARIAS, F.J.C.; RÊGO, G.M.; SILVA, A.P.G.; FERREIRA FILHO, J.R.; VANSCONCELOS, O.L. Estabilidade fenotípica de cultivares de amendoim avaliadas na região Nordeste do Brasil. Ciência e Agrotecnologia, v.23, p.808-812, 1999.

SANTOS, R.C.; GODOY, I.J.; FAVERO, A.P. Melhoramento do amendoim. In: SANTOS, R.C. (Ed.). O agronegócio do amendoim no Brasil. Campina Grande: Embrapa Algodão; Brasília: Embrapa Informação Tecnológica, 2005. p.123190.

SANTOS, R.C.; REGO, G.M.; SANTOS, C.A.; PEIXOTO, A.S.; MELO FILHO, P.A.; MORAES, T.M.G.; SUASSUNA, T.F. Recomendações técnicas para o cultivo do amendoim em pequenas propriedades agrícolas do Nordeste brasileiro. Campina Grande: Embrapa Algodão, 2006. 7p. (Embrapa Algodão. Circular técnica, 102).

SILVA, W.C.J.; DUARTE, J.B. Métodos estatísticos para estudo de adaptabilidade e estabilidade fenotípica em soja. Pesquisa Agropecuária Brasileira, v.41, p.23-30, 2006.

SUDARIC, A.; SIMIC, D.; VRATARIC, M. Characterization of genotype by environment interactions in soybean breeding programmes of Southeast Europe. Plant Breeding, v.125, p.191-194, 2006.

TÁVORA, F.J.A.F.; SILVA, F.P.; COSTA FILHO, F.V.; ALVES, J.F. Comportamento e estabilidade de produção de cultivares de amendoim. Ciências Agronômicas, v.19, p.103107,1988 .

TÁVORA, F.J.A.F.; SILVA, F.P.; MELO, F.I.O.; PITOMBEIRA, J.B.; COSTA NETO, F.V.; VIEIRA. F. Yield adaptability and stability of peanut genotypes estimated under different environments. Ciência Agronômica, v.33, p.10-14, 2002.

Recebido em 8 de janeiro de 2007 e aprovado em 1o de junho de 2007 